\title{
Effect of Pulsed Ultraviolet Light on the Total Phenol Content of Elderberry (Sambucus nigra) Fruit
}

\author{
Ramesh Murugesan*, Valérie Orsat, Mark Lefsrud \\ Department of Bioresource Engineering, Faculty of Agricultural and Environmental Sciences, Macdonald Campus, McGill Univer- \\ sity, Montréal, Canada. \\ Email: *ramesh.murugesan@mail.mcgill.ca
}

Received March 20 $0^{\text {th }}, 2012$; revised April 16 ${ }^{\text {th }}, 2012$; accepted April 23 ${ }^{\text {rd }}, 2012$

\begin{abstract}
The changes in total polyphenolics in elderberry (Sambucus nigra) following treatment with various doses of pulsed ultraviolet rays (UV) were investigated. Four pulsed UV durations $(5,10,20,30$ seconds) at three energy dosages (4500, $6000,11,000 \mathrm{~J} / \mathrm{m}^{2} /$ pulse) were considered for the research. All treated elderberry fruits were incubated for $24 \mathrm{~h}$ at room temperature $\left(25^{\circ} \mathrm{C}\right)$ following treatment to ensure enough response duration for enhanced development of polyphenols by the berries. The highest increase in total phenolics around $50 \%$ was found with $11,000 \mathrm{~J} / \mathrm{m}^{2} /$ pulse for a 10 seconds treatment while nearly $40 \%$ increase in total phenolics was found at an energy dosage of $11,000 \mathrm{~J} / \mathrm{m}^{2} /$ pulse after $5 \mathrm{sec}-$ onds exposure. Even though most of the treatments indicated an increase in total polyphenols, some treatment expressed a decrease in phenolics content when compared to untreated fruits.
\end{abstract}

Keywords: Elderberry; Antioxidant; Polyphenols; Pulsed Ultraviolet Light; Abiotic

\section{Introduction}

During growth and development, plants are subjected to diverse types of stresses, such as drought, heat, ultraviolet light, pathogen attack etc. [1]. Plants physiologically and biochemically suffer from these stresses. Generally, any changes in growth condition, of plant's natural habitat, that modifies or interrupts its metabolic homeostasis could be defined as environmental stress [2]. Such changes in growth condition involve an adjustment of the metabolic pathways, aimed at accomplishing a new state of homeostasis, in a process that is usually referred to as acclimation $[3,4]$. Several different stages are involved in this acclimation and three different types of compounds are imperative for this process. These compounds are mostly antioxidants or osmoprotectants, byproducts of stress and signal transduction molecules [2].

The signal transductions are generally categorized into two groups. First group of signal transductions could be newly synthesized compounds or compounds released from conjugated forms or different by-products of stress metabolism. The second group of signal transductions is the by-products from the membrane degradation or reactive oxygen species or phenolic compounds and antioxidants $[5,6]$.

The injuries or sufferance caused due to the stresses

${ }^{*}$ Corresponding author. are mostly reflected in the metabolic pathways [7-9], which leads to the reduction in the growth capacity of plants. Stresses such as thermal stress usually induce the production of polyphenolic compounds such as flavonoids and phenylpropanoids and there are many supportive research [10-13] confirming this phenomenon.

Polyphenols are the antioxidants which are abundantly available in our diet in fruits and vegetables. Generally, fruits and vegetables contain a variety of antioxidant compounds [14], such as polyphenolic compounds. Antioxidants such as polyphenols are important from the point of view of their free radical scavenging activity [15], and capable of preventing or reducing oxidative damage to human cells [16]. Free radicals can be defined as atoms or group of atoms with unpaired number of electrons. Free radicals are mainly formed when certain molecules interact with oxygen. The important thing about free radicals is their potential damage to cells by reacting with important cell components such as polyunsaturated fatty acids in cellular membranes, nucleotides in DNA, and critical sulfhydryl bonds in proteins [17]. These damages can lead to many diseases such as cancer [18] and accelerate the aging process [19].

Consumption of fruits and vegetables is inversely proportional to heart diseases and various cancers [20]. This character of disease prevention is mainly attributed to the presence of phytochemicals, natural antioxidants, 
fibres and other bioactive compounds [21]. Among phytochemicals of interest, the group of phenols and polyphenols exhibits excellent antioxidant properties [22]. Polyphenols are gaining attention from consumers and manufacturers as consumption of polyphenols rich fruits and vegetables or other foods and beverages may have many health benefits which include the prevention of chronic diseases such as cancer and cardiovascular diseases [23-26].

Elderberries (Sambucus nigra) are gaining attention due to their potential health promoting properties since many researchers have demonstrated the polyphenols and anthocyanin content of elderberry and their bioavailable antioxidant properties [27-29]. The color pigments from elderberry have high anthocyanin content [29], rich in organic acids, and polyphenols [30]. These properties make elderberries an attractive nutritional supplement in food applications. Elderberry has a high anthocyanin content of $863 \mathrm{mg} / \mathrm{L}$ [31]. Cyanidin-3-sambubioside and cyanidin-3-glucoside are the two major anthocyanins in elderberry and contribute around $85 \%$ of the total anthocyanins content of the fruit [32].

Elderberries are predominately grown in northern and central Europe and North America. Commercial elderberry production is mostly concentrated in the United States, Denmark, Italy, and Austria [33]. Elderberries are mainly used for the production of juice and concentrates, however they can be useful to manufacture syrup, wine, jelly, pie filling, desserts, cakes, candies, etc. [31].

The plant production of berry phenolic compounds can be induced by various abiotic stress conditions [34]. Many studies [35-38] have been conducted to enhance the nutritional value of fruits using continuous UV light as an abiotic stress. Pulsed ultraviolet light technology is generally seen as an alternative to thermal treatment of food surfaces and mainly used in microbial inactivation of food material. Non-thermal processing of foods using pulsed light technology has been shown to be an effective and attractive alternative to thermal processing of foods [39] and many researchers [40-43] demonstrated the effective use of pulsed light technology in microbial inactivation of foods. Pulsed light technology has been shown to be more effective in microbial destruction and inactivation than continuous ultraviolet light [44-46]. On the other hand, the application of Pulsed UV light technology in nutraceutical development in foods is in its budding stage and very little research has been done on using pulsed UV technology for enhancing the concentration of secondary metabolites in fruits and vegetables [47].

The enhancement of the vitamin $\mathrm{D}_{2}$ content in mushrooms using pulsed UV light technology was already demonstrated [48]. This is a good example of the potential use of pulsed UV light for the improvement of the nutritional/health properties of fruits and vegetables via plant metabolic stress response. The effective use of pulsed light technology in microbial destruction when compared to continuous UV has been established in many occasions, while the effectiveness of pulsed light on the stimulating plant metabolic response has not established. This research work was intended to demonstrate the effectiveness of pulsed light technology to enhance the polyphenolic content of elderberry fruit. It would be an important step to promote pulsed light technology in handling and post-harvest treatment of fruits and vegetables to enhance the nutraceutical content.

\section{Materials and Methods}

\subsection{Sample Preparation}

Matured, fully ripen elderberry (Sambucus nigra) fruits were selectively harvested from a farm located in Franklin, Quebec, Canada, and brought into the laboratory. The harvested elderberries were cleaned manually in order to remove foreign materials and insects. The cleaned elderberries were stored at $4^{\circ} \mathrm{C}$ refrigeration temperature prior to pulsed UV treatment. The fruits were brought to room temperature just before the pulsed UV treatment and following the pulsed UV treatment the elderberries were stored at $4^{\circ} \mathrm{C}$ refrigerated temperature for 24 hours to ensure enough time to the hormetic response (plant metabolic stress response) from the fruit. After pulsed $\mathrm{UV}$ treatment, the berries were kept under deep freeze at the temperature of $-80^{\circ} \mathrm{C}$ until further processing or analysis.

\subsection{Reagents and Standards}

Sodium Carbonate (anhydrous), Folin-Ciocalteu reagent, Gallic acid (anhydrous) and deionised water were used in the experiment. All reagents and chemicals used were of analytical grade (Fisher Scientific International, Inc.).

\subsection{Pulsed UV Light System}

The Xenon pulsed UV system RC-747 (Figure 1) was used in the experiment. The pulsed UV system consists of three major components and they are,

1) Power and control module;

2) UV heating chamber;

3) Cooling system.

The power and control module has all the controls necessary for operating the pulsed UV treatment (treatment duration, treatment intensity etc.). The UV heating chamber consists of a UV lamp and sample holder. The UV lamp is placed at the top-middle of the chamber and the systemis secured by a door to prevent UV light leakage. The sample holder can be placed inside the chamber 


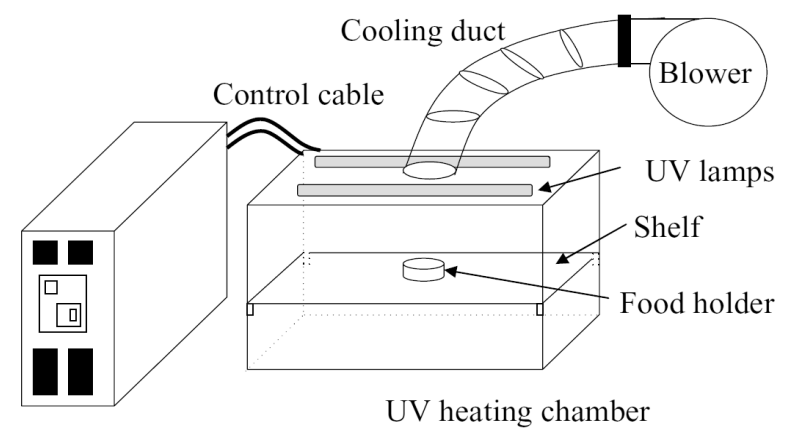

Power and control module

Figure 1. Schematic diagram of Xenon Pulsed UV system [42].

at various heights thus achieving different distances from the UV light source. The energy received by the sample holder varies, depending upon the distance from the UV source and the energy received was calculated by following the equipment's calibration. A cooling system was connected to the UV heating chamber to cool the system during the treatment. The cooling system draws the air inside the UV chamber using a motor and a duct connected to the UV heating chamber. The UV system has a capacity of pulsed ultra violet light energy from 0 to $12,000 \mathrm{~J} / \mathrm{m}^{2} /$ pulse at the rate of 3 pulses per second.

\subsection{Pulsed UV Light Treatment Setup}

The total area of the sample holder plate in the pulsed UV system was $0.061845 \mathrm{~m}^{2}$ which was divided into five different zones (Figure 2) to check the effect of pulsed UV light at various locations on the holding plate. Zones "B", "C", "E", and "F" are divided equally with the area of $0.0103075 \mathrm{~m}^{2}$ and the zone " $\mathrm{R}$ " was establishedwith the area of $0.00555 \mathrm{~m}^{2}$ just below the UV light. Three energy levels were considered for the experiment i.e. 4500, 6000 and 11,000 J/m $/ \mathrm{m}^{2} /$ pulse and four treatment durations were considered namely 5, 10, 20 and $30 \mathrm{~s}$. The elderberries were treated with pulsed UV light in the system at all three energy levels with all possible duration and zone placement combinations. All 60 treatments were completed in triplicates. At the end of each treat- ment experiment, the elderberry fruits were stored for 24 $\mathrm{h}$ under refrigerated conditions to ensure enough response duration for the stress induced response development of polyphenols in the berries. After the $24 \mathrm{~h}$ rest period following treatment, the total polyphenols contents of berries were analyzed and percentage gain was calculated in comparison with control fruits (untreated).

\subsection{Determination of Polyphenolic Content}

The total polyphenolic content was determined using Folin-Ciocalteu method. The absorbance was measured at $765 \times 10^{-9} \mathrm{~m}$ with a spectrophotometer (BIOCHROMUltrospec $\left.1000^{\mathrm{TM}}\right)$. The results were expressed in milligrams of gallic acid equivalents (GAE) per $0.1 \mathrm{~kg}$ of fresh weight of fruit.

\subsection{Statistical Analysis}

A three-level Analysis of Variance (ANOVA) was carried out with the confidence level of $95 \%(\mathrm{P} \leq 0.05)$ to determine the significant difference of pulsed UV treatment effect on total polyphenolic content of elderberries using the GLM model method. SAS (Windows version 9.2) software was used for the statistical analysis and Microsoft Excel (Windows version 12) was used to interpret the results. The statistical analysis results were presented in Table 1.

\section{Results and Discussion}

Researchers have demonstrated the effect of ultraviolet light treatment to improve the shelf life of fruits by surface disinfection [49-52] however, very few have explored its effect on nutritional content and specifically the concentration of secondary metabolites of health enhancing benefits such as antioxidants [53,54].

Enhancement of flavonoids content by UV treatment in Faba bean leaves and birch leaves have been demonstrated [55,56]. Flavonoids increase in Faba bean (Vicia $a b a$ L. cv. Broad Windsor) leaves was determined following UV exposure [55]. Similarly, an increase in several flavonoids with condensed tannins was found in

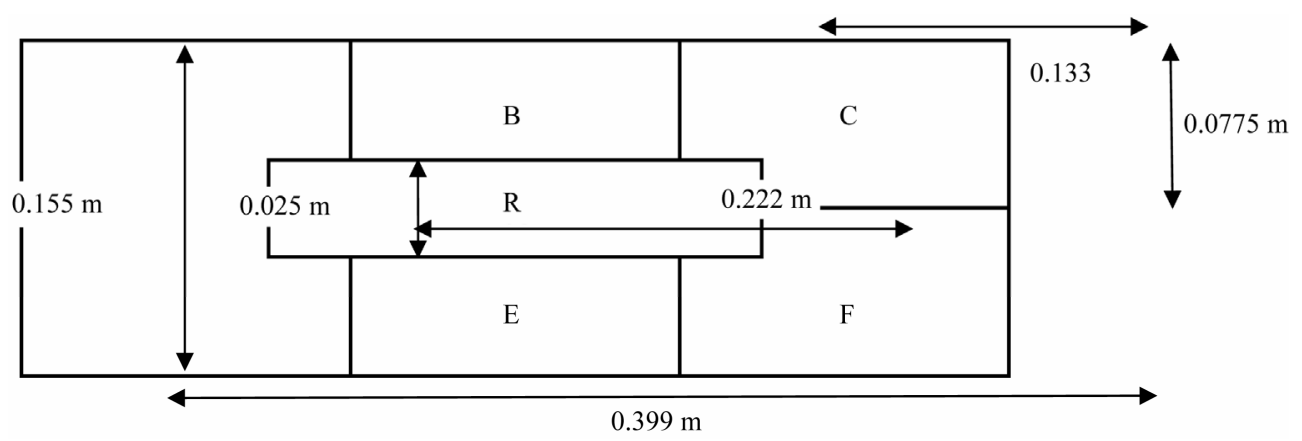

Figure 2. Zones arrangement on the holding plate. 
Table 1. Statistical analysis of pulsed ultraviolet treatments.

\begin{tabular}{|c|c|c|c|c|c|}
\hline Source & $\mathrm{DF}$ & Type III SS & Mean Square & F Value & $\operatorname{Pr}>F$ \\
\hline Zone & 4 & 306.228267 & 76.557067 & 2.05 & 0.091 \\
\hline Time & 3 & 5713.797958 & 1904.599319 & 50.91 & $<0.0001$ \\
\hline Energy & 2 & 8701.560248 & 4350.780124 & 116.3 & $<0.0001$ \\
\hline Zone and Time & 12 & 337.266209 & 28.105517 & 0.75 & 0.6991 \\
\hline Zone and Energy & 8 & 568.998363 & 71.124795 & 1.9 & 0.0641 \\
\hline Time and Energy & 6 & 5288.173806 & 881.362301 & 23.56 & $<0.0001$ \\
\hline
\end{tabular}

birch leaves following exposures to UV-B [56]. This indicates that UV treatments can have an impact in stimulating the synthesis of plant's secondary metabolites such as polyphenols.

The pulsed light treatment was given to the whole elderberry fruits. The fruits were placed on the sample holder in the UV heating chamber and the pulsed light treatment was given for the specified time determined by the experimental setup. Elderberry fruits were turned manually twice during the treatment to ensure even application of pulsed light to the elderberry fruit's surface. The sample holder was placed at different locations away from the lamp to get the specified energy levels. The treatment results were plotted in a chart as a function of the zones of exposure, presenting zones on the $\mathrm{x}$ axis and percentage polyphenolic gain on the y axis. The polyphenolic content increase or decrease in the berries as a result of each treatment is shown in Figures 3-6.

All treatment durations (such as 5, 10, 20, 30 seconds) showed no particular trend. For example, 5 seconds treatment (Figure 3) at $4500 \mathrm{~J} / \mathrm{m}^{2} /$ pulse and $11,000 \mathrm{~J} / \mathrm{m}^{2} /$ pulse treatments showed an overall percentage increase in polyphenolic content for all zones, while the energy level of $6000 \mathrm{~J} / \mathrm{m}^{2} /$ pulse showed mixed results of increase and decrease in phenolic content in 5 seconds treatment of pulsed light. Except for zones " $F$ " \& "E", all zones actually expressed a decrease in polyphenolic content with $6000 \mathrm{~J} / \mathrm{m}^{2} /$ pulse energy level. The polyphenolic content was decreased by $4.95 \%$ in zone "R", by $0.88 \%$ in zone "C" and $6.22 \%$ in zone "B". However, zones "E" and " $F$ " showed an increase of $7.66 \%$ and $0.61 \%$ for the same treatment.

Similar results were observed in continuous type UV treatment for strawberry [57]. They found there is no significant difference between lower dosage and higher dosage UV treatment of strawberries. Likewise, in an experiment it was found that there was no significant difference between two energy levels of 250 and 1000 $\mathrm{J} / \mathrm{m}^{2}$ in terms of anthocyanin enhancement, however color development followed by UV plus white light treatment in royal Gala apple was dose dependent [58]. Similarly, in the current elderberry experiment, the pulsed UV treatment did not follow any specific trend to increase or decrease the phenolic content of elderberry fruits in these particular energy levels.

The energy level of $4500 \mathrm{~J} / \mathrm{m}^{2} /$ pulse increased the phenolic content in all zones following 5 seconds pulsed light treatment. Zone " $\mathrm{R}$ " was the highest increase in polyphenolic content of $16.87 \%$ and zone "B" showed the lowest increase with $5.8 \%$ (Figure 3). Even though, the $4500 \mathrm{~J} / \mathrm{m}^{2} /$ pulse energy level increased the phenolic content in all zones, the standard deviations of the replicates were higher when compared to results obtained at the energy level of $11,000 \mathrm{~J} / \mathrm{m}^{2} /$ pulse. The energy level of $11,000 \mathrm{~J} / \mathrm{m}^{2} /$ pulse resulted in higher phenolic content development when compared to other energy levels for the 5 seconds duration treatment. The energy level increased the phenolic content ranging from $42.95 \%$ to $47.9 \%$ as compared to non-treated control samples. Zone "B" obtained the highest increase (47.9\%) among all zones in the same treatment duration, but the statistical analysis showed that the zones were not the deciding factor to the increase or decrease in the phenolic content of the fruit subjected to pulsed UV treatment.

The 10 seconds treatments followed a trend similar to the 5 seconds treatment in the increasing or decreasing effects on the total polyphenolics contents. Likewise, with the exception of the energy level of $6000 \mathrm{~J} / \mathrm{m}^{2} /$ pulse, all energy levels and zone combinations brought an increase in the phenolic content of the berry fruit. Both the 5 seconds and 10 seconds treatments at the energy levels of $4500 \mathrm{~J} / \mathrm{m}^{2} /$ pulse and $11,000 \mathrm{~J} / \mathrm{m}^{2} /$ pulse showed increase in phenolic content in all zones while the energy level of $6000 \mathrm{~J} / \mathrm{m}^{2} /$ pulse showed mixed results. This trend of polyphenolic content increase or decrease changed for the $20 \mathrm{~s}$ and $30 \mathrm{~s}$ treatment durations. The results from the $20 \mathrm{~s}$ and $30 \mathrm{~s}$ duration treatments were not consistent in all zones and showed increase as well as decrease in different zones for the same energy level (Figures 5 and 6).

Interestingly, pulsed light treatment significantly increased the temperature of the elderberry fruit. The temperature rise was depended upon the energy level and the treatment duration. The higher energy level and higher 


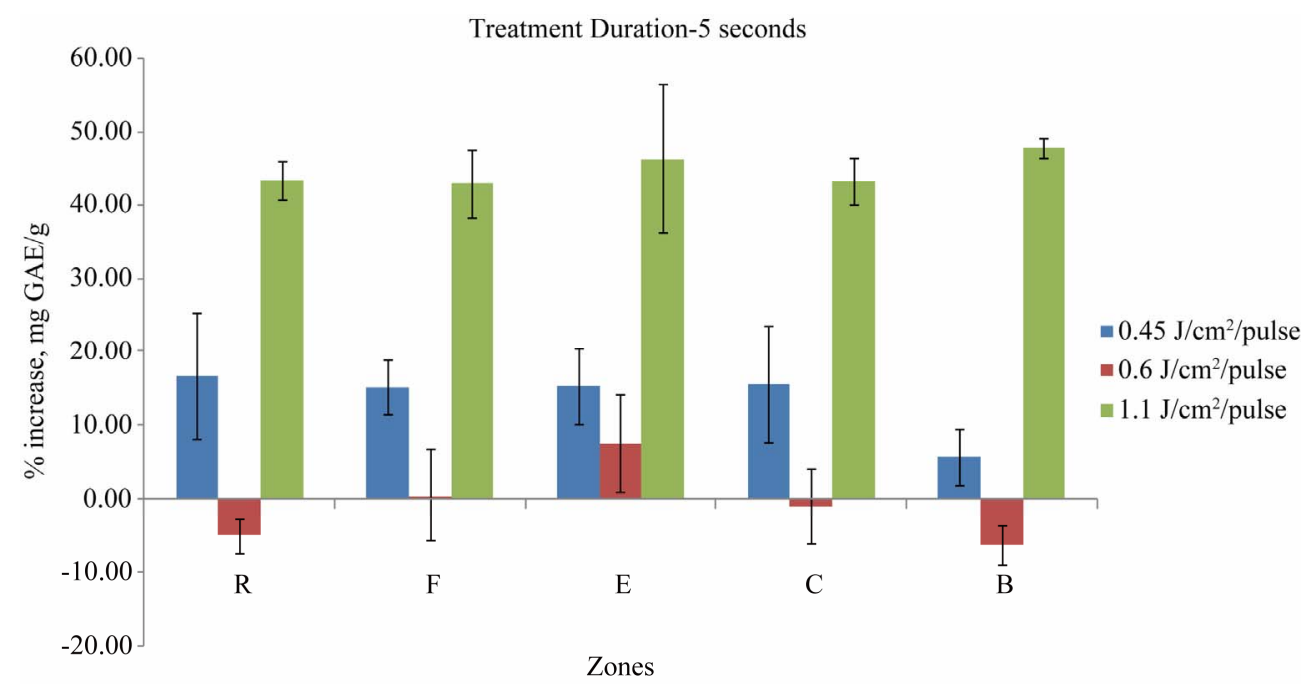

Figure 3. Percentage gain in mg GAE/g in $5 \mathrm{~s}$ treatment duration for different energy pulses and different exposure zones.

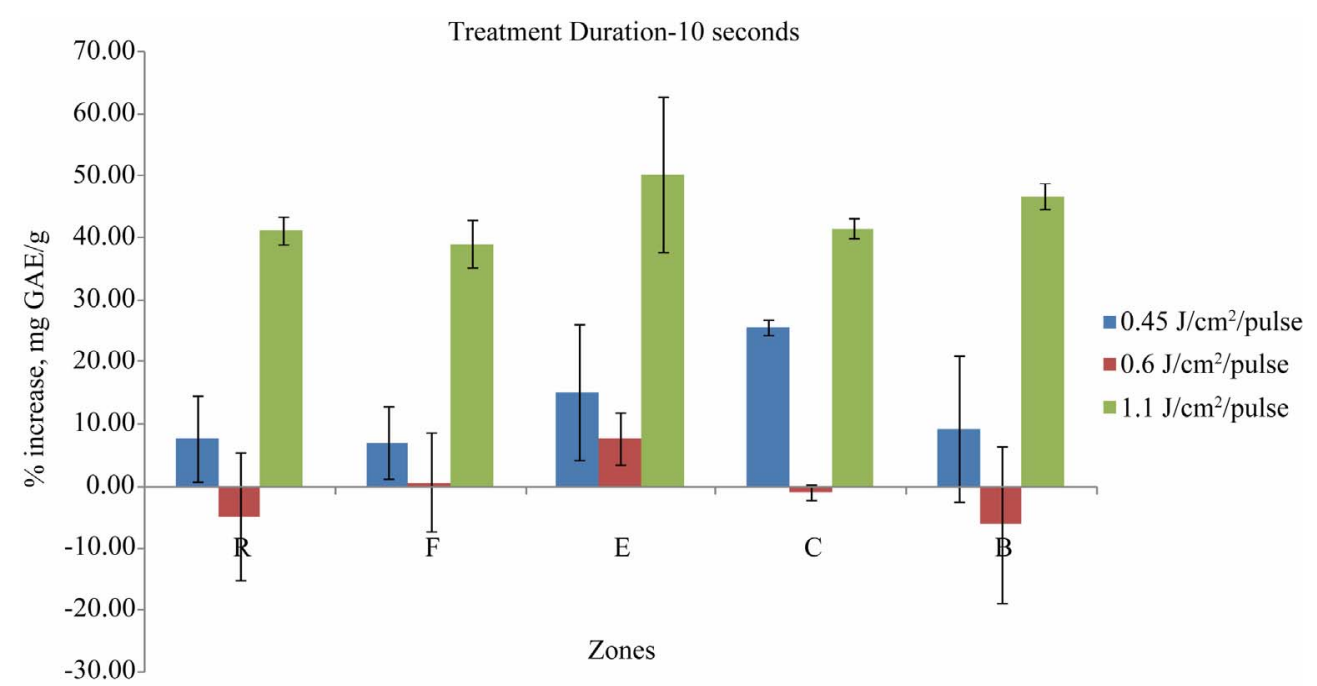

Figure 4. Percentage gain in $\mathbf{m g}$ GAE/g in $10 \mathrm{~s}$ treatment duration for different energy pulses and different exposure zones.

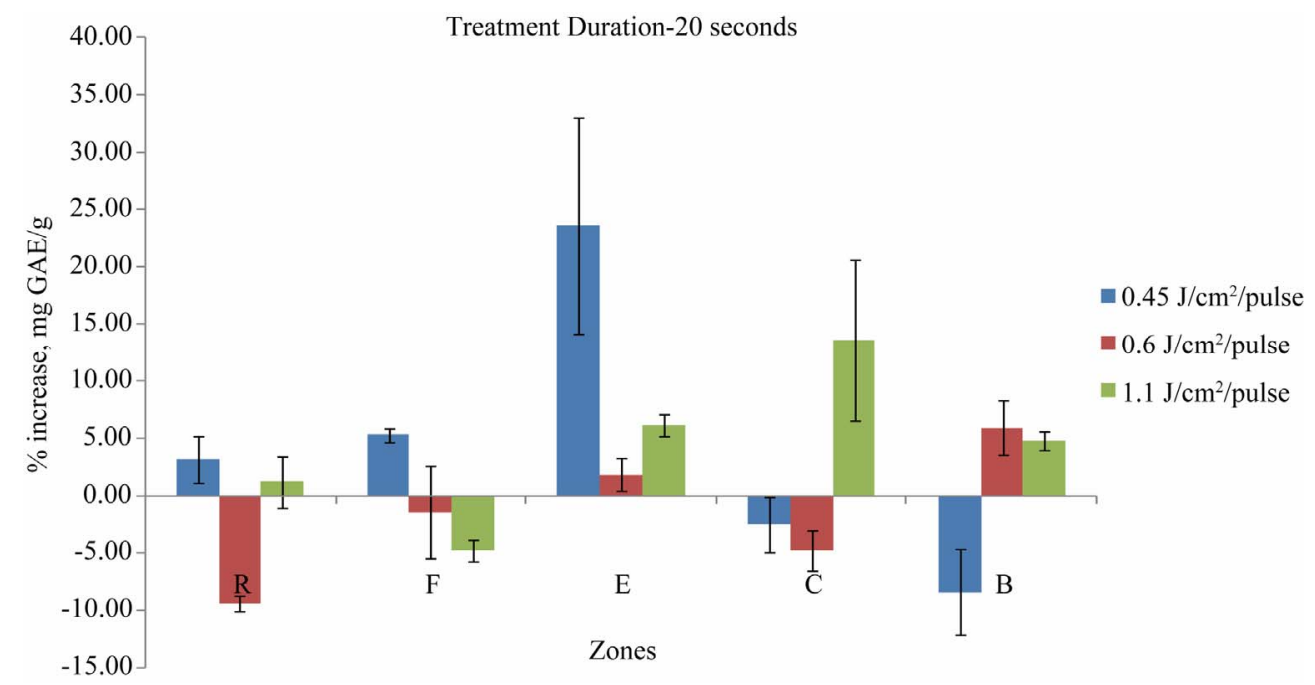

Figure 5. Percentage gain in $\mathrm{mg} \mathrm{GAE} / \mathrm{g}$ in $20 \mathrm{~s}$ treatment duration for different energy levels and different exposure zones. 


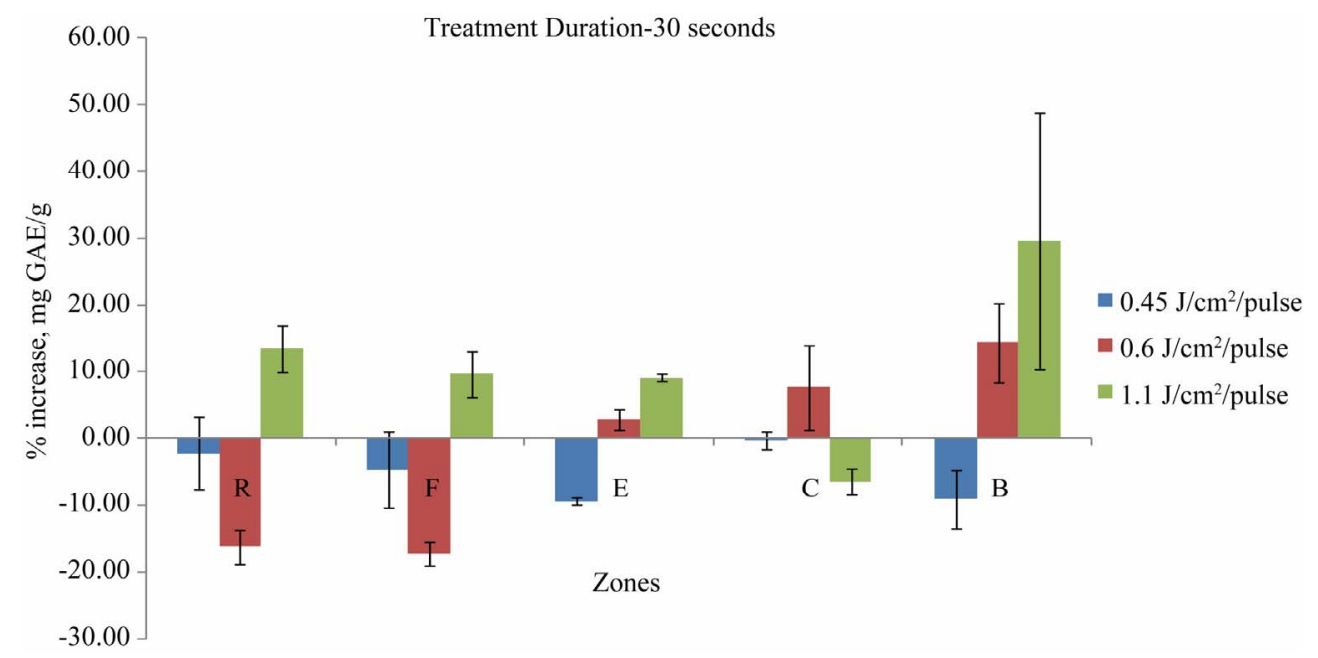

Figure 6. Percentage gain in $\mathrm{mg} \mathrm{GAE} / \mathrm{g}$ in $30 \mathrm{~s}$ treatment duration for different energy levels and different exposure zones.

treatment durations produced more heat on the fruit when compared to the lower energy level and lower treatment duration. Hence, the pulsed light treatment caused two different stresses on the elderberry fruit, the stress caused by the pulsed UV light and the thermal stress created by the UV light's temperature increase on the surface of the fruits. Thermal stresses have also been demonstrated to induce the production of phenolic compounds in plants. Through increased activity of Phenylalanine ammonialyase (PAL) is considered to be the primary enzyme of the phenylpropanoid pathway [59], where this enzyme catalyzes the transformation of 1-Phenyalanine into transcinnamic acid, by deamination which is the prime intercessor in the biosynthesis of phenolics in plants $[60,61]$. Phenylalanine ammonia-lyase stimulated and increases in activity in the response to the thermal stress and imperative in terms of cell acclimation against stress in plants $[59,61,62]$.

Even though the thermal stress can be applied to increase or induce the development of secondary metabolites such as phenolic compounds in plants, there are some limitations on the dosage of the thermal stress that can be tolerated by the plant. Over dosage of thermal stress can definitely produce sever damages to the plant or fruits and these damages are mostly irreversible. Similarly with the pulsed light treatment, the higher energy level of $11,000 \mathrm{~J} / \mathrm{m}^{2} /$ pulse for durations of $30 \mathrm{sec}-$ onds slightly damaged the fruit's skin with apparent skin discoloration. It implies that only limited dosage of the pulsed light should be applied to the elderberry fruit and product damage could be the reason for the mixed results obtained with the 20 and 30 seconds treatments at higher energy levels.

The phenolic content of the fruit increased at the energy level of $4500 \mathrm{~J} / \mathrm{m}^{2} /$ pulse followed by a decrease for the energy level of $6000 \mathrm{~J} / \mathrm{m}^{2} /$ pulse, while $11,000 \mathrm{~J} / \mathrm{m}^{2}$ / pulse energy level increased the phenolic content of the fruit to highest level when compared to the other two energy levels. The increase or decrease followed a particular pattern in elderberry fruit as clearly seen from trends presented in Figures 7 and 8. These trend graphs were plotted by taking energy level and treatment duration in the $\mathrm{x}$-axis and phenolic content increase in the $\mathrm{y}$-axis. The mean values are connected by a line to illustrate an increasing or decreasing trend. The trend which polyphenols follow to increase or to decrease, in response to plant metabolic activity can be quite interesting. The change in color parameters in apples due to UV treatment was dose dependent [58], however our pulsed UV treatment did not follow any definite trends for increase or decrease.

The statistical analyses of the results expressed very interesting findings. Zones within the UV treatment chamber were not a significant or a deciding factor in the increase or decrease of the phenolic content following pulsed ultraviolet treatment. Even the combination of zone \& time and zone \& energy were not significant factor combinations $(\operatorname{Pr}=0.6991 \& 0.0641)$. However, time with energy combination was a significant factor in all zones $(\mathrm{Pr}<0.0001)$ for the pulsed UV treatment. This concludes that the pulsed UV light had a relatively uniform energy distribution throughout the sample holder or treatment plate of the equipment (Figure 2).

The energy level of $11,000 \mathrm{~J} / \mathrm{m}^{2} /$ pulse with the treatment duration of $5 \mathrm{~s}$ and $10 \mathrm{~s}$ were the best combinations tested to enhance the polyphenol content in elderberry fruit. Among these two, $10 \mathrm{~s}$ treatment was the best treatment which gave more than $50 \%$ increase in the polyphenolic content of the fruit.

\section{Summary and Conclusion}

Antioxidant properties of fruits and vegetables are mostly 


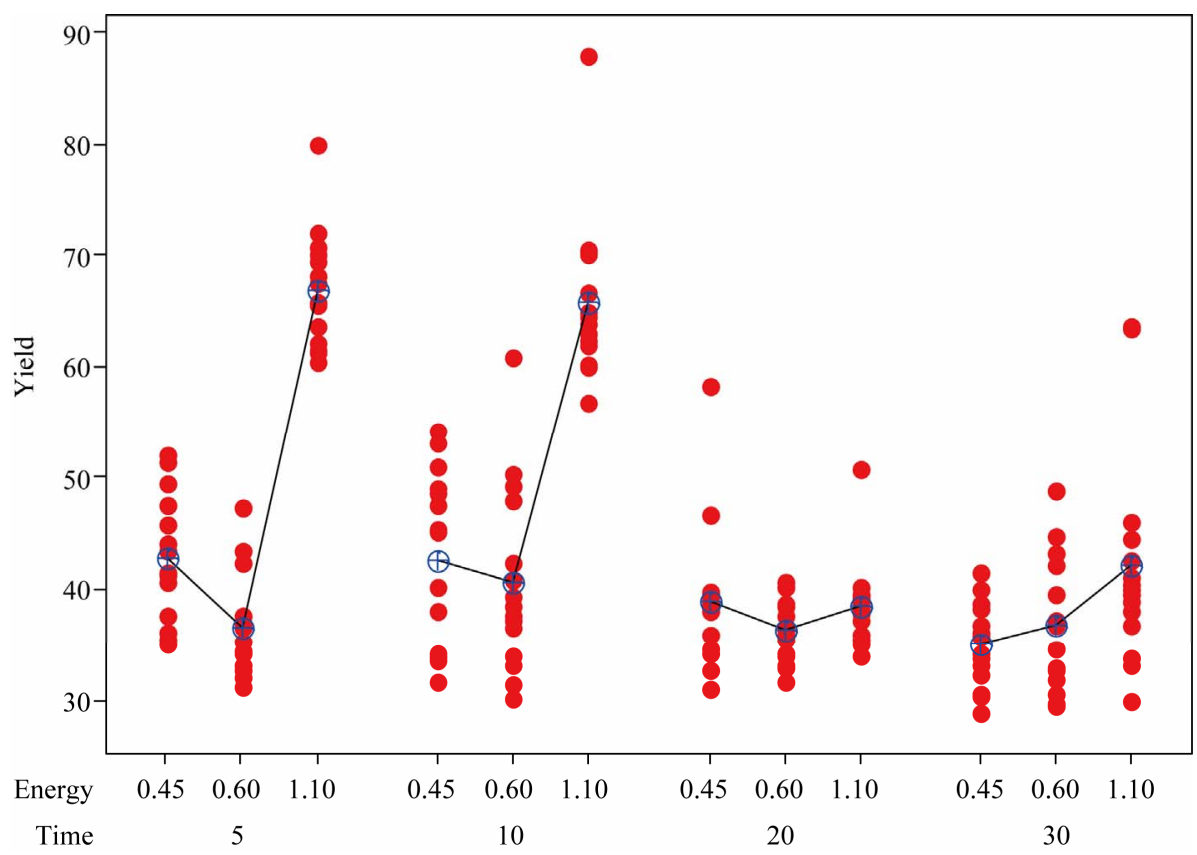

Figure 7. Individual value plots of yield for treatment duration and energy.

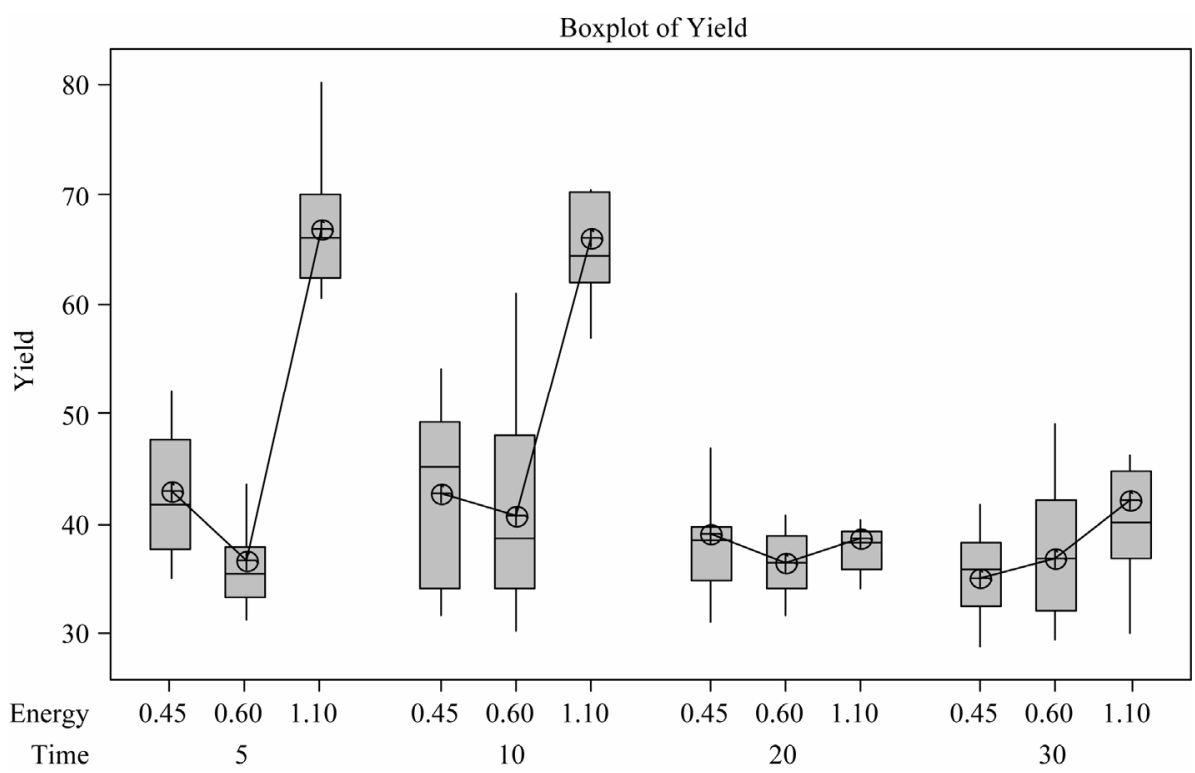

Figure 8. Box plot of yield for different energy and treatment duration.

diminished by processing and storage. It is imperative to enhance fruits and vegetables antioxidant capacity to balance the losses during processing of foods. There are very limited methods or protocols to enhance the antioxidants, especially phenolic compounds, in fruits and vegetables. It is essential to develop such methods to enhance the nutraceutical properties of the fruits and vegetables.

Pulsed UV light treatments enhanced the antioxidant properties of elderberry fruits by increasing their total polyphenolic content. This illustrates the potential use of pulsed UV light to enhance the nutritional content of fruits and vegetables. The highest increase of polyphenols with minimum deviations was found at the energy level of $11,000 \mathrm{~J} / \mathrm{m}^{2} /$ pulse with a treatment duration of 10 seconds. Interestingly the increase of energy from $4500 \mathrm{~J} / \mathrm{m}^{2} /$ pulse to $6000 \mathrm{~J} / \mathrm{m}^{2} /$ pulse brought a decrease in the phenolic content of the fruit and this trend was found in all treatment durations with the exception of the $30 \mathrm{~s}$ treatment.

This indicates that there is a specific treatment intensity to be respected to ensure a positive hormetic effect 
on the treated fresh fruits. At this point it is not clear that the enhancement of phenolic content of elderberry fruit is due solely to thepulsed light treatment. There is a chance that the thermal stress which was developed during the pulsed light treatment might contribute fully or partially to the increase of the phenolic content of the elderberry fruit. Further investigation is required to determine whether the pulsed light or the thermal stress is responsible for the enhancement of phenolic compounds. Finding the pulsed light or thermal stress responsive polyphenol or group of polyphenols would be the proposed next stage of this research. This research might open up pathways to the adoption of pulsed UV light technology in the nutraceutical oriented food industry.

\section{REFERENCES}

[1] B. D. McKersie and Y. Y. Leshem, "Stress and Stress Coping in Cultivated Plants," Kluwer Academic Publishers, London, 1994, p. 256.

[2] V. Shulaev, D. Cortes, G. Miller and R. Mittler, "Metabolomics for Plant Stress Response," Physiologia Plantarum, Vol. 132, No. 2, 2008, pp. 199-208. doi:10.1111/j.1399-3054.2007.01025.x

[3] M. Ron, "Abiotic Stress, the Field Environment and Stress Combination," Trends in Plant Science, Vol. 11, No. 1, 2006, pp. 15-19. doi:10.1016/i.tplants.2005.11.002

[4] N. Suzuki and R. Mittler, "Reactive Oxygen Species and Temperature Stresses: A Delicate Balance between Signaling and Destruction," Physiologia Plantarum, Vol. 126, No. 1, 2006, pp. 45-51. doi:10.1111/j.0031-9317.2005.00582.x

[5] R. Mittler, S. Vanderauwera, M. Gollery and F. Van Breusegem, "Reactive Oxygen Gene Network of Plants," Trends in Plant Science, Vol. 9, No. 10, 2004, pp. 490498. doi:10.1016/j.tplants.2004.08.009

[6] M. Ron, "Oxidative Stress, Antioxidants and Stress Tolerance," Trends in Plant Science, Vol. 7, No. 2, 2002, pp. 405-410.

[7] M. D. Anderson, T. K. Prasad, B. A. Martin and C. R. Stewart, "Differential Gene Expression in Chilling-Acclimated Maize Seedlings and Evidence for the Involvement of Abscisic Acid in Chilling Tolerance," Plant Physiology, Vol. 105, 1994, pp. 331-339.

[8] T. K. Prasad, M. D. Anderson and C. R. Stewart, "Acclimation, Hydrogen Peroxide, and Abscisic Acid Protect Mitochondria against Irreversible Chilling Injury in Maize Seedlings," Plant Physiology, Vol. 105, No. 2, 1994, pp. 619-627.

[9] T. K. Prasad, M. D. Anderson, B. A. Martin and C. R. Stewart, "Evidence for Chilling-Induced Oxidative Stress in Maize Seedlings and a Regulatory Role for Hydrogen Peroxide," The Plant Cell Online, Vol. 6, No. 1, 1994, pp. 65-74. doi:10.1105/tpc.6.1.65

[10] A. K. Bharti and J. P. Khurana, "Mutants of Arabidopsis as Tools to Understand the Regulation of Phenylpropanoid Pathway and UVB Protection Mechanisms,"
Photochemistry and Photobiology, Vol. 65, No. 5, 1997, pp. 765-776. doi:10.1111/j.1751-1097.1997.tb01923.x

[11] P. J. Christie, M. R. Alfenito and V. Walbot, "Impact of Low-Temperature Stress on General Phenylpropanoid and Anthocyanin Pathways: Enhancement of Transcript Abundance and Anthocyanin Pigmentation in Maize Seedlings," Planta, Vol. 194, No. 4, 1994, pp. 541-549. doi: $10.1007 / \mathrm{BF} 00714468$

[12] R. A. Dixon and N. L. Paiva, "Stress-Induced Phenylpropanoid Metabolism," The Plant Cell, Vol. 7, No. 7, 1995, pp. 1085-1097.

[13] C. Nozzolillo, P. Isabelle and G. Das, "Seasonal Changes in the Phenolic Constituents of Jack Pine Seedlings (Pinus banksiana) in Relation to the Purpling Phenomenon," Canadian Journal of Botany, Vol. 68, 1990, pp. 2010-2017.

[14] H. Wang, G. Cao and R. L. Prior, "Oxygen Radical Absorbing Capacity of Anthocyanins," Journal of Agricultural and Food Chemistry, Vol. 45, No. 2, 1997, pp. 304-309. doi:10.1021/jf960421t

[15] Y. Z. Fang, S. Yang and G. Wu, "Free Radicals, Antioxidants, and Nutrition," Nutrition, Vol. 18, No. 10, 2002, pp. 872-879. doi:10.1016/S0899-9007(02)00916-4

[16] A. L. Dawidowicz, D. Wianowska and B. Baraniak, "The Antioxidant Properties of Alcoholic Extracts from Sambucus nigra L. (Antioxidant Properties of Extracts)," Food Science and Technology, Vol. 39, No. 3, 2006, pp. 308-315.

[17] L. Machlin and A. Bendich, "Free Radical Tissue Damage: Protective Role of Antioxidant Nutrients," FASEB Journal, Vol. 1, No. 6, 1987, pp. 441-445.

[18] B. Halliwell, "Free Radicals and Antioxidants: A Personal View," Nutrition Reviews, Vol. 52, No. 8, 1994, pp. 253-265. doi:10.1111/j.1753-4887.1994.tb01453.x

[19] D. Harman, "The Aging Process," Proceedings of the National Academy of Sciences of the United States of America, Vol. 78, No. 11, 1981, pp. 7124-7128. doi:10.1073/pnas.78.11.7124

[20] J. Beattie, A. Crozier and G. G. Duthie, "Potential Health Benefits of Berries," Current Nutrition and Food Science, Vol. 1, No. 1, 2005, pp. 71-86. doi:10.2174/1573401052953294

[21] M. C. Nicoli, M. Anese and M. Parpinel, "Influence of Processing on the Antioxidant Properties of Fruit and Vegetables," Trends in Food Science \& Technology, Vol. 10, No. 3, 1999, pp. 94-100. doi:10.1016/S0924-2244(99)00023-0

[22] E. A. Decker, "The Role of Phenolics, Conjugated Linoleic Acid, Carnosine, and Pyrroloquinoline Quinone as Nonessential Dietary Antioxidants," Nutrition Reviews, Vol. 53, No. 3, 1995, pp. 49-58. doi:10.1111/j.1753-4887.1995.tb01502.x

[23] C. Manach, A. Scalbert, C. Morand, C. Remesy and L. Jimenez, "Polyphenols: Food Sources and Bioavailability," American Journal of Clinical Nutrition, Vol. 79, No. 5, 2004, pp. 727-747.

[24] A. Scalbert and G. Williamson, "Dietary Intake and Bioavailability of Polyphenols," Journal of Nutrition, Vol. 
130, No. 8, 2000, pp. 2073-2085.

[25] K. A. Steinmetz and J. D. Potter, "Vegetables, Fruit, and Cancer Prevention: A Review," Journal of the American Dietetic Association, Vol. 96, No. 10, 1996, pp. 10271039. doi:10.1016/S0002-8223(96)00273-8

[26] L. B. M. Tijburg, T. Mattern, J. D. Folts, U. M. Weisgerber and M. B. Katan, "Tea Flavonoids and Cardiovascular Diseases: A Review," Critical Reviews in Food Science and Nutrition, Vol. 37, No. 8, 1997, pp. 771-785. doi:10.1080/10408399709527802

[27] G. Cao and R. L. Prior, "Anthocyanins Are Detected in Human Plasma after Oral Administration of an Elderberry Extract," Clinical Chemistry, Vol. 45, No. 4, 1999, pp. 574-576.

[28] P. E. Milbury, G. Cao, R. L. Prior and J. Blumberg, "Bioavailablility of Elderberry Anthocyanins," Mechanisms of Ageing and Development, Vol. 123, No. 8, 2002, pp. 997-1006. doi:10.1016/S0047-6374(01)00383-9

[29] M. Netzel, G. Strass, M. Herbst, H. Dietrich, R. Bitsch, I. Bitsch and T. Frank, "The Excretion and Biological Antioxidant Activity of Elderberry Antioxidants in Healthy Humans," Food Research International, Vol. 38, No. 8-9, 2005, pp. 905-910. doi:10.1016/j.foodres.2005.03.010

[30] R. Veberic, J. Jakopic, F. Stampar and V. Schmitzer, "European Elderberry (Sambucus nigra L.) Rich in Sugars, Organic Acids, Anthocyanins and Selected Polyphenols," Food Chemistry, Vol. 114, No. 2, 2009, pp. 511515. doi:10.1016/j.foodchem.2008.09.080

[31] J. J. Vulić, L. O. Vračar and Z. M. Šumić, "Chemical Characteristics of Cultivated Elderberry Fruit," Acta Periodica Technologica, Vol. 39, 2008, pp. 85-90.

[32] J. P. Goiffon, P. P. Mouly and E. M. Gaydou, "Anthocyanic Pigment Determination in Red Fruit Juices, Concentrated Juices and Syrups Using Liquid Chromatography," Analytica Chimica Acta, Vol. 382, No. 1-2, 1999, pp. 39-50. doi:10.1016/S0003-2670(98)00756-9

[33] J. Lee and C. E. Finn, "Anthocyanins and Other Polyphenolics in American Elderberry (Sambucus canadensis) and European Elderberry (Sambucus nigra) Cultivars," Journal of the Science of Food and Agriculture, Vol. 87, No. 14, 2007, pp. 2665-2675. doi:10.1002/jsfa.3029

[34] R. Puupponen-Pimiä, L. Nohynek, H. L. Alakomi and K. M. Oksman-Caldentey, "Bioactive Berry CompoundsNovel Tools against Human Pathogens," Applied Microbiology and Biotechnology, Vol. 67, No. 1, 2005, pp. 8-18. doi:10.1007/s00253-004-1817-x

[35] O. Arakawa, "Effect of Ultraviolet Light on Anthocyanin Synthesis in Light Colored Sweet Cherry," Japanese Society for Horticultural Science, Vol. 62, No. 3, 1993, pp. 543-546. doi: $10.2503 /$ jjshs. 62.543

[36] M. Baka, "Photochemical Treatment to Improve Storability of Fresh Strawberries," Journal of Food Science, Vol. 64, No. 6, 1999, pp. 1068-1072. doi:10.1111/j.1365-2621.1999.tb12284.x

[37] E. Cantos, J. C. Espin and F. A. Tomas-Barberan, "Postharvest Induction Modeling Method Using UV Irradiation Pulses for Obtaining Resveratrol-Enriched Table Grapes. A New Functional Fruit?" Journal of Agricultural and
Food Chemistry, Vol. 49, No. 10, 2001, pp. 5052-5058. doi:10.1021/jf010366a

[38] E. Cantos, J. C. Espin, M. J. Fernandez, J. Oliva and F. A. Tomas-Barberan, "Postharvest UV-C Irradiated Grapes as a Potential Source for Producing Stilbene-Enriched Red Wines," Journal of Agricultural and Food Chemistry, Vol. 51, No. 5, 2003, pp. 1208-1214. doi:10.1021/jf020939z

[39] J. A. Guerrero-Beltran and G. V. Barbosa-Canovas, "Advantages and Limitations on Processing Foods by UV Light," Food Science and Technology International, Vol. 10, No. 3, 2004, pp. 37-147.

[40] K. L. Bialka and A. Demirci, "Efficacy of Pulsed UVLight for the Decontamination of Escherichia coli O157:H7 and Salmonella spp. on Raspberries and Strawberries," Journal of Food Science, Vol. 73, No. 5, 2008, pp. M201-M207. doi:10.1111/j.1750-3841.2008.00743.x

[41] S. L. Hillegas and A. Demirci, "Inactivation of Clostridium Sporogenes in Clover Honey by Pulsed UV-Light Treatment," E-Journal-CIGR, 2003.

[42] S. Jun, J. Irudayaraj, A. Demirci and D. Geiser, "Pulsed UV-Light Treatment of Corn Meal for Inactivation of Aspergillus Niger Spores," International Journal of Food Science \& Technology, Vol. 38, No. 8, 2003, pp. 883-888. doi:10.1046/j.0950-5423.2003.00752.x

[43] K. Krishnamurthy, A. Demirci and J. Irudayaraj, "Inactivation of Staphylococcus aureus in Milk and Milk Foam by Pulsed UV-Light Treatment and Surface Response Modeling," Transactions of the ASABE, Vol. 51, No. 6, 2008, pp. 2083-2090.

[44] F. Fine and P. Gervais, "Efficiency of Pulsed UV Light for Microbial Decontamination of Food Powders," Journal of Food Protection, Vol. 67, No. 4, 2004, pp. 787 792.

[45] K. F. McDonald, R. D. Curry, T. E. Clevenger, K. Unklesbay, A. Eisenstark, J. Golden and R. D. A. Morgan, "Comparison of Pulsed and Continuous Ultraviolet Light Sources for the Decontamination of Surfaces," IEEE Transactions on Plasma Science, Vol. 28, No. 5, 2000, pp. 1581-1587. doi:10.1109/27.901237

[46] J. T. O. Dunn and W. Clark, "Pulsed Light Treatment of Food and Packaging," Food Technology, Vol. 49, No. 9, 1995, pp. 95-98.

[47] L. Palmieri and D. Cacace, "High Intensity Pulsed Light Technology. Emerging Technologies for Food Processing," Elsevier Academic Press, London, 2005.

[48] M. D. Kalaras and R. B. Beelman, "Vitamin D2 Enrichment in Fresh Mushrooms Using Pulsed UV Light Department of Food Science," Penn State University, University Park, 2010.

http://foodscience.psu.edu/directory/rbb6/VitaminDEnric hment.pdf

[49] S. Ben-Yehoshua, V. Rodov, J. J. Kim and S. Carmeli, "Preformed and Induced Antifungal Materials of Citrus Fruits in Relation to the Enhancement of Decay Resistance by Heat and Ultraviolet Treatments," Journal of Agricultural and Food Chemistry, Vol. 40, No. 7, 1992, pp. 1217-1221. doi:10.1021/jf00019a029

[50] D. Marquenie, C. W. Michiels, A. H. Geeraerd, A. 
Schenk, C. Soontjens, J. F. Van Impe and B. M. Nicolaï, "Using Survival Analysis to Investigate the Effect of UV-C and Heat Treatment on Storage Rot of Strawberry and Sweet Cherry," International Journal of Food Microbiology, Vol. 73, No. 2-3, 2002, pp.187-196. doi:10.1016/S0168-1605(01)00648-1

[51] D. Marquenie, J. Lammertyn, A. H. Geeraerd, C. Soontjens, J. F. Van Impe, B. M. Nicolaï and C. W. Michiels, "Inactivation of Conidia of Botrytis Cinerea and Monilinia Fructigena Using UV-C and Heat Treatment," International Journal of Food Microbiology, Vol. 74, No. 1-2, 2002, pp. 27-35.

[52] J. Pan, A. R. Vicente, G. A. Martínez, A. R. Chaves and P. M. Civello, "Combined Use of UV-C Irradiation and Heat Treatment to Improve Postharvest Life of Strawberry Fruit," Journal of the Science of Food and Agriculture, Vol. 84, No. 14, 2004, pp. 1831-1838. doi:10.1002/jsfa. 1894

[53] M. Adrian, P. Jeandet, A. C. Douillet-Breuil, L. Tesson and R. Bessis, "Stilbene Content of Mature Vitis vinifera Berries in Response to UV-C Elicitation," Journal of Agricultural and Food Chemistry, Vol. 48, No. 12, 2000, pp. 6103-6105. doi:10.1021/jf0009910

[54] E. Cantos, J. C. Espin and F. A. Tomas-Barberan, "Postharvest Stilbene-Enrichment of Red and White Table Grape Varieties Using UV-C Irradiation Pulses," Journal of Agricultural and Food Chemistry, Vol. 50, No. 22, 2002, pp. 6322-6329. doi:10.1021/jf020562x

[55] S. D. Flint, P. W. Jordan and M. M. Caldwell, "Plant Protective Response to Enhanced UV-B Radiation under Field Conditions. Leaf Optical Properties and Photosynthesis," Photochemistry and Photobiology, Vol. 41, No. 1, 1985, pp. 95-99. doi:10.1111/j.1751-1097.1985.tb03454.x

[56] A. Lavola, "Accumulation of Flavonoids and Related Compounds in Birch Induced by UV-B Irradiance," Tree
Physiology, Vol. 18, No. 1, 1998, pp. 53-58. doi:10.1093/treephys/18.1.53

[57] M. Baka, J. Mercier, R. Corcuff, F. Castaigne and J. Arul, "Photochemical Treatment to Improve Storability of Fresh Strawberries," Journal of Food Science, Vol. 64, No. 6, 1999, pp. 1068-1072. doi:10.1111/j.1365-2621.1999.tb12284.X

[58] Y. H. Dong, D. Mitra, A. Kootstra, C. Lister and J. Lancaster, "Postharvest Stimulation of Skin Color in Royal Gala Apple," Journal of the American Society for Horticultural Science, Vol. 120, No. 1, 1995, pp. 95-100.

[59] A. Kacperska, "Water Potential Alteration-A Prerequisite or a Triggering Stimulus for the Development of Freezing Tolerance in Overwintering Herbaceous Plants?" In: P. H. Li and L. Christerson, Eds., Advances in Plant Cold Hardiness, CRC Press, Boca Raton, 1993, pp. 7391.

[60] R. A. Dixon, A. D. Choudhary, D. Dalkin, R. Edwards, T. Fahrendorf, G. Gowri, M. J. Harrison, C. J. Lamb, G. J. Loake, C. A. Maxwell, J. Orr and N. L. Paiva, "Molecular Biology of Stress-Induced Phenylpropanoid and Isoflavonoid Biosynthesis in Alfalfa," In: H. A. Stafford and R. K. Ibrahim, Eds., Phenolic Metabolism in Plants, Plenum press, New York, 1992, pp. 91-138. doi:10.1007/978-1-4615-3430-3 4

[61] A. Levine, R. Tenhaken, R. Dixon and C. Lamb, " $\mathrm{H}_{2} \mathrm{O}_{2}$ from the Oxidative Burst Orchestrates the Plant Hypersensitive Disease Resistance Response," Cell, Vol. 79, 1994, pp. 583-593. doi:10.1016/0092-8674(94)90544-4

[62] A. Leyva, J. A Jarillo, J. Salinas and J. M. Martinez-Zapater, "Low Temperature Induces the Accumulation of Phenylalanine Ammonia-Lyase and Chalcone Synthase mRNAs of Arabidopsis Thaliana in a Light-Dependent Manner," Plant Physiology, Vol. 108, No. 1, 1995, pp. 39-46. 